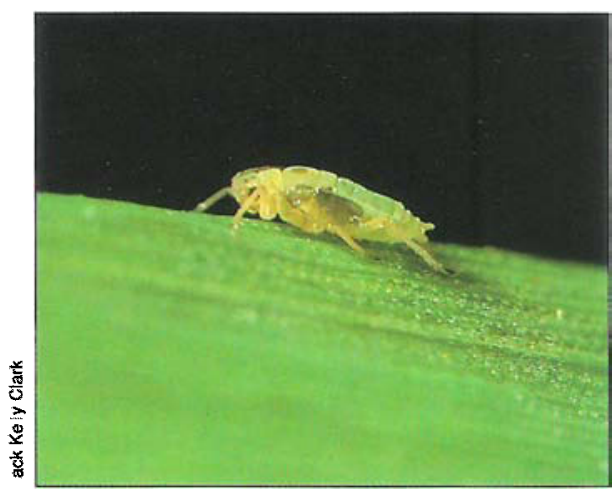

Adult Russian wheat aphid.

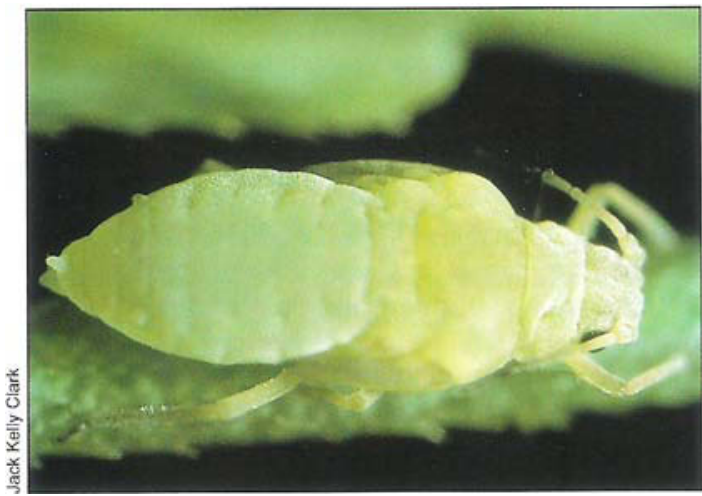

View of aphid from above showing characteristic short antennae, double tail, and very short cornicles (small tubelike projections on each side of the aphid).

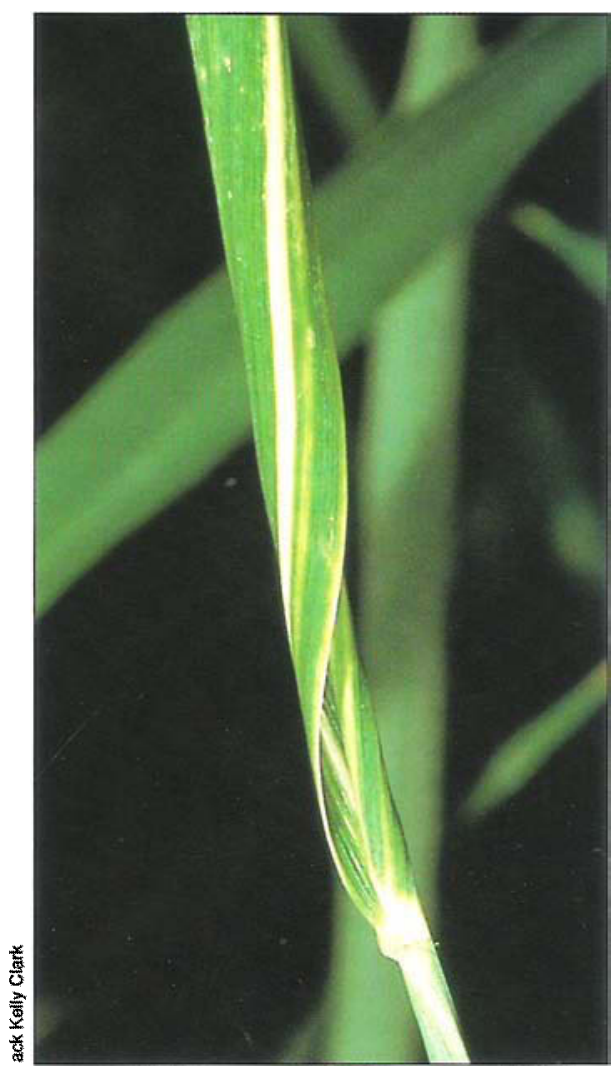

Typical Russian wheat aphid damage showing curled leaf and white streaking.

\title{
Russian wheat aphid: natural enemies, resistant wheat offer potential control
}

\author{
D. González $\quad \square \quad$ Charles G. Summers $\quad$ Calvin O. Qualset
}

A severe pest of small grains, Russian wheat aphid has been spreading throughout all of California's cereal-growing regions for nearly 4 years. Coordinated research to develop economically and environmentally acceptable management strategies for this pest is in progress.

In March 1986, Russian wheat aphid (RWA), Diuraphis noxia (Mordvilko), was first reported present in the United States, causing crop losses in small grains in Texas. Since then, it has spread, infesting small grains in Oklahoma, Kansas, Nebraska and South Dakota and moving west to California, Oregon and Washington. Crop losses in 1988 were an estimated $\$ 130$ million, 2.4 times greater than in 1987. Losses since 1986 have exceeded $\$ 500$ million.

Russian wheat aphid is a small, pale green insect, often covered with a white powdery coating of wax. It prefers to colonize areas deep in the whorl or beneath the leaf sheath, but as aphid numbers increase, the entire plant may be colonized. A cool-season aphid, it causes damage from late fall through spring. While feeding, RWA injects into the plant a toxic saliva that destroys chlorophyll, resulting in white or cream-colored streaks on stems and leaves. The toxin also causes leaves to twist and curl like a soda straw.

In California, wheat and barley are apparently the most susceptible crops, followed by rye and triticale. Oats also host RWA, but suffer only marginal injury. The RWA does not attack or injure corn, rice, or sorghum. It does, however, colonize many native and introduced grasses.

The aphid first appeared in Imperial County in March 1988 and in Yolo County the following May. It has since spread to all of California's major cereal-growing regions (fig. 1). Losses in California's cereal crops during the 1988-1989 growing season, including control costs, are estimated at $\$ 8$ million, according to the Great Plains Agricultural Council. Losses in rangeland grasses have not been determined.
Damage from RWA infestations include direct economic losses due to insect feeding and indirect losses due to costs of insecticides and their application. Damage estimates do not include environmental and social costs or the concerns associated with combatting RWA infestations with insecticides. At present, insecticides are the only RWA control tactic available to California farmers. Continued use of these agents will destroy native natural enemies, accelerate development of insecticide resistance in RWA and other insect pests, and upset secondary pests. The results, short-term, are induced pest outbreaks. The results, long-term, are contamination of soil and water, wildlife losses, and general environmental degradation. Economically, too, the extensive acreage planted with small grains, depressed markets and decreased prices make unilateral chemical protection a poor option.

Furthermore, untreated small grains normally host native natural enemies, providing natural control of potential primary and secondary pests in their crops and in adjacent crops. Enhancing biological control of RWA will minimize insecticide use and permit maximum impact from native natural enemies in cereals and associated agroecosystems.

After a 3-year exploration for RWA natural enemies in Central Asia, D. González and others documented that RWA has not been a pest on small grains. In these areas the aphid has been associated with cereals for more than 50 years. In the 3 years of exploration several potentially effective species (or biotypes) of natural enemies and many different potentially resistant wheat varieties have been identified from in and around Central Asia. These should be evaluated in the United States to advance biological control and host plant resistance of RWA.

Our ongoing and proposed assessment of biological control/host plant resistance/chemical assessment (economic thresholds) are summarized here. The report reflects a summary of RWA research coordinated by UC researchers $D$.

González and C. G. Summers in biological control, C. G. Summers and C. O. Qualset in host plant resistance, and C. G. Summers 


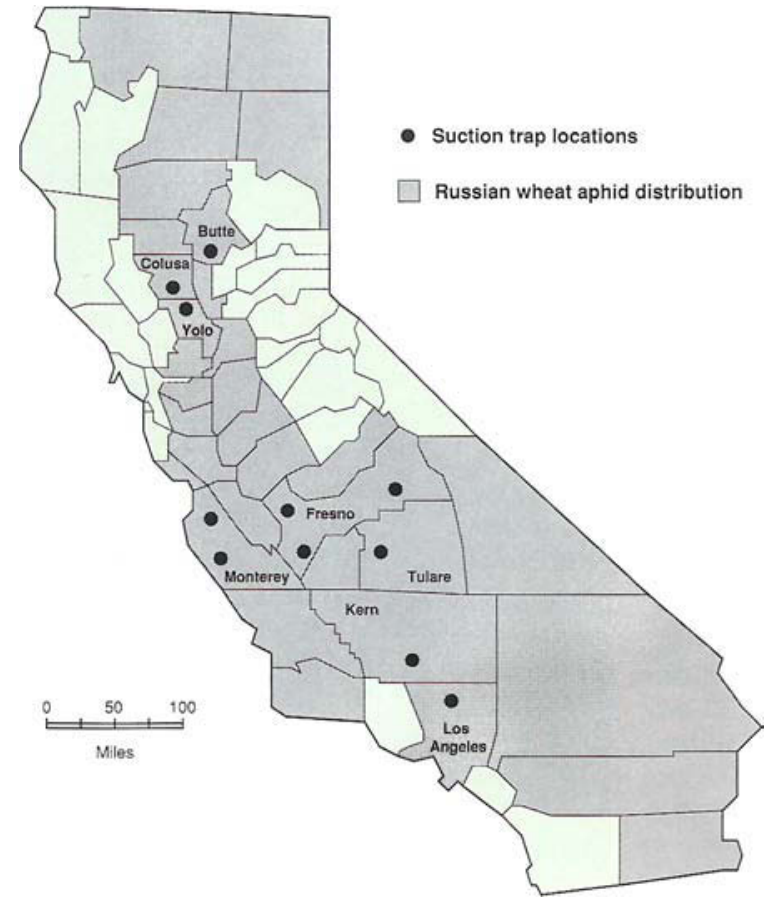

Fig. 1. Current distribution of Russian wheat aphid in California and location of suction traps.

in migration and economic thresholds. Our studies are based on observations and reports on RWA in fields in and around Central Asia as well as on previous experiences in alfalfa with spotted alfalfa aphid and blue alfalfa aphid. Both alfalfa pests initially caused extensive damage in alfalfa throughout the western United States, but the combination of biological control and host plant resistance reduced both pests to little economic significance.

\section{Biological control}

In California, biological control efforts against RWA include a preliminary assessment of native natural enemies attacking RWA before introduction of exotic enemies; foreign exploration to determine the type and extent of mortality factors associated with RWA outside the United States, where this species has existed in low numbers for a long time, and preliminary selective introduction of five exotic parasite species.

Surveys for native natural enemies. Indigenous primary parasites attacking RWA in the United States include Lysiphlebus testaceipes, Diaeretiella rapae and Aphelinus varipes. Several species of coccinellid and dipterous predators also attack RWA and other aphids on small grains. However, the extant aphid natural enemy species in the United States do not effectively control RWA. In California, native natural enemies are associated with only moderate to high RWA numbers late in the season and are rarely inside curled leaves. Therefore, effective biological control will require importing new and exotic natural enemies from Central Asia, where natural enemies control this aphid.

Foreign exploration. Scientists in State Agricultural Experiment Stations (SAES), USDA-Agricultural Research Service (ARS), and the USDAAnimal and Plant Health Inspection Service (APHIS) cooperated in 1988-1991 to import and establish natural enemies of RWA in the United States. Foreign exploration has resulted in importation and culture of more than 124 source populations of natural enemies, including parasites and predators. These foreign explorations also produced information on (1) the frequent occurrence (in several locations in several countries) in or near Central Asia of several parasite species routinely associated with low densities of RWA, (2) effective parasitization of RWA under a wide range of climatic conditions, and (3) parasitization of RWA inside curled leaves. This information, plus experience with the imported natural enemies, causes us to believe that five of the exotic parasites merit further study: D. rapae, Aphelinus asychis, Aphelinus varipes, Aphidius colemani and Aphidius matricarae.

Introduction of exotic parasites. The five species of RWA parasites noted have been released, in collaboration with USDA-APHIS, in selective fields in California's Imperial, Riverside, Santa Barbara, Fresno, Sacramento, and Yolo counties, with the assistance of local farm advisors. Sites for release were selected on the basis of variations in different habitats and climatic patterns in the following growth zones: southern low desert, southern in-

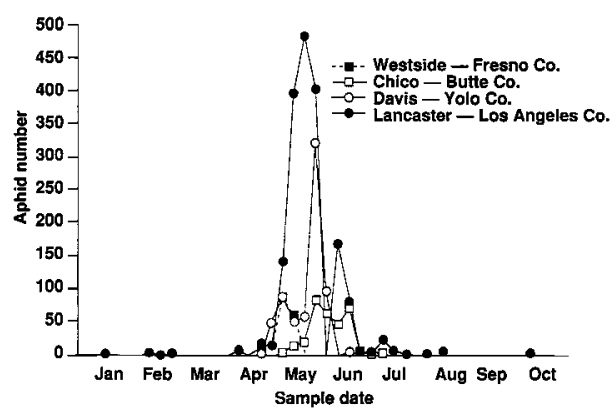

Fig. 2. Flight pattern of Russian wheat aphid representing the high desert (L.A. Co.), San Joaquin Valley (Fresno Co.), Sacramento Valley (Yolo Co.) and Northern Sacramento Valley (Butte Co). land valley, southern coastal valley, central inland valley and northern inland valley. These represent the climatic zones in which most wheat is grown in California. They also represent varied environmental and climatic conditions under which the impact against RWA of the same exotic species and/or biotypes of natural enemies can be assessed.

\section{Migration and flight activity}

With the aid of a statewide network of suction traps (fig. 1), UC scientists are studying migration and flight activity of RWA. These studies are part of a larger migration study being conducted throughout the aphid's range. A pattern of migration and movement of winged aphids is emerging that will help determine whether planting dates can be manipulated within the constraints of field access, wheat maturity and crop rotation to avoid or escape these dispersal flights and thus prevent infestation when the crop is immature and most susceptible. While too few data have been collected to describe a predictable pattern of aphid movement, a small flight apparently occurs in fall and a much larger flight during spring (fig. 2). Occasionally, small flights occur in midwinter. Planting so that cereals do not emerge until after the fall flight but mature to at least flowering before the spring flight may enable growers to avoid much of the wheat injury caused by RWA. Planting trials that encompass dates from October through February are underway at the Kearney Agricultural Center and West Side Field Station to obtain empirical data on aphid numbers and yield response as they relate to time of planting and infestation.

\section{Economic thresholds}

Short-term, chemical intervention offers the most effective and immediate control of RWA. Development of economic thresholds for RWA is underway at the Kearney Agricultural Center as part of a cooperative Western Regional project. These thresholds will be dynamic and reflect the plant growth stage (age) at initial infestation and the degree of aphid damage (number of tillers infested) and aphid density. Preliminary data show that aphid infestations on young plants can result in extensive plant mortality and that plants are susceptible to injury and yield loss as late as head emergence (table 1).

Russian wheat aphid is susceptible to all of the common insecticides used for aphid control in small grains; there are no known cases of aphid resistance. The aphid is, however, difficult to control because of its ability to roll leaves into a tubelike structure that insecticides cannot penetrate. Therefore, treatment decisions 
should be made before injury reaches this stage. Some control may be obtained after this stage if the weather is warm and the insecticide chosen has some vapor or systemic action. Insecticide treatments at planting are not recommended because there are no procedures available to predict whether a field is infected with RWA. Likewise, such treatments will not last long enough to provide protection throughout the period for potential injury. Growers should contact their local farm advisor for information on economic thresholds as they develop and proper choice of insecticides.

\section{Host plant resistance}

The development of host plant resistance offers the most economical and least environmentally disruptive strategy for managing RWA in California. Combined with biological control provided by predators and parasites already described, these strategies could largely eliminate the need for chemical intervention. Evaluations of RWA resistance under California field conditions have been made with wheat and triticale germplasm from UC Davis, International Maize and Wheat Improvement Center (CIMMYT Mexico), International Center for Agricultural Research in the Dry Areas (ICARDA Syria), and Iran. Material has been employed from breeding programs in Oklahoma, Colorado and the USDA National Small Grains Collection at Aberdeen, Idaho. Communication with workers in Colorado, Idaho, Oregon and Oklahoma has been maintained to avoid duplication of efforts.

Materials were tested at the Kearney Agricultural Center in Parlier. Entries were hand-planted in mid-December, with each entry replicated twice. Beginning in early February, plants were infested weekly with greenhouse-reared RWA. Infestations continued until plants began flowering. Following flowering, plants were rated visually for their reaction to RWA on a 1-to-9 scale. Plants rated 1 to 3 showed little or no injury and were con-

TABLE 1. Mean ( \pm S.E.) grain yields (g) from greenhouse-grown wheat plants infested with RWA at five different growth stages

\begin{tabular}{llc}
\hline $\begin{array}{l}\text { Growth stage } \\
\text { at infestation }\end{array}$ & \multicolumn{2}{c}{$\begin{array}{c}\text { Grain yield } \\
\text { in grams }\end{array}$} \\
\hline Two leaves & Tran \\
Tillering & $0.00 \ddagger$ & $\pm 0.00 \mathrm{a}$ \\
Jointing & $0.00 \ddagger$ & $\pm 0.00 \mathrm{a}$ \\
Flag leaf & 1.87 & $\pm 0.31 \mathrm{~b}$ \\
Head emergence & 2.32 & $\pm 0.16 \mathrm{bc}$ \\
Noninfested & 2.73 & $\pm 0.26 \mathrm{C}$ \\
& 3.98 & $\pm 0.23 \mathrm{~d}$
\end{tabular}

"Means followed by the same letter(s) are not significantly different at $P=0.05$, Duncan's Multiple Range Test.

†Average of 10 plants.

†Plant died before producing seed. sidered resistant. Those ranking 4 to 6 showed some streaking and chlorosis (yellowing) and were regarded as intermediate in response. Plants rated 7 to 9 exhibited extensive chlorosis and streaking, were often near death, and were considered susceptible. Emphasis was placed on wheat and triticale because these two sources, if resistant, can be used directly in developing resistant wheat varieties for California, but the tests also included barley and rye.

Two UC Davis primary octoploid triticales (CI81 and CI82), developed in a breeding program at Davis in the 1970s and found to be resistant in Oklahoma, also were resistant at the Kearney Agricultural Center ( 2.0 and 2.5 scores, respectively). The third triticale, C187, was intermediate in score (5.5) and probably is not useful for breeding.

A group of 99 durum wheat breeding lines from UC Davis and from ICARDA did not show useful resistance. However, in a group of 103 Iranian bread wheats, 9 scored 2 and 27 scored 3; thus, more than $25 \%$ of that group were worthy of more testing. Previously, workers in South Africa and at several U.S. sites found that some wheats from West Asia have good resistance to RWA. California and CIMMYT common wheat breeding lines and varieties uniformly were susceptible, with average scores of 7.65 and 7.66 , respectively. This confirms the need for introducing resistance genes into California wheats. Meanwhile, hexaploid triticale varieties adapted to California conditions appeared to be damaged less by RWA (means score of 5.3 for 23 included in the test) than currently available common wheat varieties (mean score of 7.1), and could be considered for production in areas where RWA infestation is anticipated to be heavy or for forage uses of cereal grains until effective resistance is developed.

A breeding program to introduce host plant resistance genes from nonadapted wheats to California varieties was initiated in 1990 . For 15 crosses, pollen from two resistant accessions was taken directly from the test plot at KAC to greenhouse-grown plants at Davis. PI94460 (score 2.0) and PI294994 (score 2.0) were used as resistant sources. Six additional crosses involved PI137739 and PI94355 as resistant sources. $\mathrm{F}_{1}$ 's have been backcrossed to California breeding lines and varieties and grown in the summer nursery in 1991. Hybrid seeds were shared with CIMMYT-Mexico where $\mathrm{F}_{1}$ 's were grown in 1990-1991.

\section{Summary}

Based on personal observations in and around Central Asia, unpublished information from farmers, researchers and ex- tension personnel in those areas and from published reports, we believe that RWA in California can be managed effectively. Considering the wide range of habitats and climatic conditions that RWA occupies in western North America (from central Mexico to Canada and particularly California), we propose several strategies to reduce its economic impact. For example, several combinations of host plant varieties and natural enemy species and/ or biotypes will be needed to effectively reduce RWA numbers in different environments. Our future plans include assessing the effectiveness of introduced biological control agents, host plant resistance, and economic threshold information and resources. Ultimately, integration of this information will result in a workable plan for managing RWA in field situations. First, however, we need detailed evaluations of available natural enemy and plant species and/or biotypes to select optimal species, insect and plant races or biotypes for the different California wheat growth areas. We will continue to screen available material for genetic resistance. When found, these entries will be distributed to others and used to enhance RWA resistance in California wheats. Russian wheat aphid resistance will be combined with resistance to Septoria tritici blotch, barley yellow dwarf virus, stripe rust and leaf rust so that California wheat production will be protected against major pests and pathogens with minimal use of pesticides. Resistance to RWA should be introduced into barley as well. In biological control a search will continue for the most effective RWA natural enemy biotype and/or species. We will concentrate in the Tian Shan and Kunloon mountain valleys of China, where for more than 20 years RWA has been known to occur infrequently. When RWA are present, numbers are low and are always associated with the presence of several natural enemies.

D. González is Entomologist, UC Riverside; C. G. Summers is Associate Entomologist, UC Berkeley (located at Kearney Agricultural Center), and C. O. Qualset is Professor, Agronomy and Range Science, UC Davis.

The authors acknowledge funding for portions of this research from the California Wheat Commission, the California Crop Improvement Association, the UCIPM Project, USDAAPHIS, USDA-ARS, and USDA-CSRS Special Grant No. 90-34205-5174. The authors wish to thank A. Newton, H. Vogt, C. Wick, S. Scardaci, W. Johnson, P. Mauk, R. Coviello, A. Fulton, W. Bentley, W. Chaney, S. Orloff, W. Bendixen, E. Natwick, R. Deerberg, L. Wendel (USDA-APHIS), R. Leon-Lopez (INIFAP), as well as J. Zhang, G. Zhang and R. Wang of the People's Republic of China for assistance with many aspects of this research. 